Int. J. Electrochem. Sci., 13 (2018) 9693 - 9700

\title{
Study of Discharge Process Final Voltage Influence on Parameters of Generalized Peukert's Equation for Nickel- Cadmium Batteries
}

\author{
Nataliya N. Yazvinskaya, Nikolay E. Galushkin*, Dmitriy N. Galushkin.
}

Don State Technical University, Laboratory of electrochemical and hydrogen energy, 147 Shevchenko Street, Town of Shakhty, Rostov Region, Russia, 346500.

*E-mail: galushkinne@mail.ru

doi: $10.20964 / 2018.10 .40$

Received: 18 March 2018 / Accepted: 20 July 2018 / Published: 1 September 2018

In this paper, the Peukert's generalized equation $C=C_{m} /\left(1+\left(i / i_{0}\right)^{n}\right)$ is proposed to describe the dependence between a battery's capacity and discharge current for nickel-cadmium batteries. It was proved by experiments that this equation is good for the description of batteries' capacity at any discharge currents unlike the classical Peukert's equation, which is inapplicable at small discharge currents. Further, all the parameters of this equation have a clear electrochemical sense. The dependence of the parameters of the Peukert's generalized equation was studied both: batteries' nominal capacity and their discharge process' final voltage. It was proved that the parameter $n$ does not depend on a batteries nominal capacity but instead does depend on a final discharge voltage. The empiric dependences of the parameters $C_{m}$ and $i_{0}$ were found on batteries' nominal capacity and final discharge voltage.

Keywords: model, battery, nickel-cadmium, capacity, discharge current

\section{FULL TEXT}

(C) 2018 The Authors. Published by ESG (www.electrochemsci.org). This article is an open access article distributed under the terms and conditions of the Creative Commons Attribution license (http://creativecommons.org/licenses/by/4.0/). 